\title{
К МЕХАНИЗМУ ФОТОИНИЦИИРОВАННОГО ОКИСЛЕНИЯ АЛКИЛБЕНЗОЛСУЛЬФОНАТОВ В ВОДНОЙ СРЕДЕ
}

\author{
V. TSEKULAJEV, M. GUBERGRITS. ALKOULBENSOOLSULFONAATIDE FOTOINITSIEERITUD \\ OKSODEERIMINE VEES \\ V. TCHEKULAYEV, M. GUBERGRITS. ON THE MECHANISM OF ALKYLBENZOSULPHONATES \\ PHOTOINITIATED OXIDATION IN AQUEOUS MEDIA
}

В настоящем сообщении рассмотрены результаты очередного этапа изучения кинетики и механизма фотоинициированного окисления модельных алкилбензолсульфонатов (АБС) - широко распространенных синтетических ПАВ - в водной среде.

В дополнение к серии линейных АБС с числом атомов углерода в алкильной цепи от 8 до 12 и размещением в ней бензольного кольца в положении 1 нами были синтезированы также два изомера - 2- и 4-додецилбензолсульфонаты, включенные в число объектов исследования.

\section{Методика эксперимента}

Схема экспериментальной установки, в которой в качестве источника УФ-излучения с интенсивностью $\approx 1 \cdot 10^{16} \kappa в а н т / \mu л \cdot c$ была использована ртутно-кварцевая лампа высокого давления СВД-120A, и методика кинетического исследования описаны в [']. Эксперимент проведен при комнатной температуре $\left(25 \pm 1^{\circ} \mathrm{C}\right)$ и исходной концентрации реагентов $6,54 \cdot 10^{-5} \mathrm{M}$. Изменение концентрации АБС в реакционной смеси во времени определялось спектрофотометрически на приборе Specord (ГДР) по интенсивности поглощения на волне 224 нм с учетом фона.

В ходе специального наладочно-методического эксперимента установлено, что непосредственное использование азура или метиленового голубого для определения концентрации АБС в реакционной смеси неприменимо, поскольку мешающее влияние некоторых продуктов реакции дает искаженные (завышенные) результаты. Разделение реакционной смеси в тонком слое активной окиси алюминия и последующее определение концентрации АБС с азуром дают результаты, удовлетворительно совпадающие с данными описанного выше спектрофотометрического анализа, и могут быть использованы для макрокинетического определения.

\section{Результаты исследования и их обсуждение}

Обработка полученных результатов показывает, что скорость фотоокислительного превращения всех изученных модельных АБС одинакова и их реакционная способность не зависит от размеров алкильного заместителя и положения в нем бензольного ядра. Это явление, несколько 
неожиданное, можно объяснить лишь специфическим механизмом фотоокислительного превращения АБС, для угтановления которого нами было предпринято несколько специальных экспериментов.

В первой их группе предстояло выявить роль синглетно-возбужденного кислорода, которая обычно значительна при фотохимическом превращении ненасыщенных органических соединений. Этот активный окислительный агент $\mathrm{O}_{2}^{1}$ образуется при триплет-триплетном взаимодействии возбужденной органической молекулы и кислорода. Использование тушителей синглетного кислорода - азида натрия, триэтиламина - в описанном эксперименте показало, что наличие их не отражается на скорости превращения АБС. Окисление тех же модельных АБС в тяжелой воде (в этой среде время жизни $\mathrm{O}_{2}^{1}$ примерно в 10 раз больше, чем в обычной воде) также не сопровождалось изменением скорости их превращения.

Таким образом, активное участие синглетно-возбужденного кислорода в фотоинициированном окислении изучаемых молекул и присущий ему специфический механизм превращения в данном случае исключаются.

На рис. 1 охарактеризовано изменение кинетики фотоокислительного превращения одного из модельных АБС (его замедления) в присутствии эквимолярной добавки аскорбиновой кислоты - известного эффективного акцептора анион-радикала кислорода $\mathrm{O}_{2}^{-} \quad\left[{ }^{2}\right]$. Последний образуется в данной системе предположительно вследствие образования из возбужденной молекулы АБС ее катион-радикала и гидратированного электрона, эффективно захватываемого молекулярным кислородом.

Анион-радикал кислорода быстро протонирует (при $\mathrm{pH} \approx 5$ ) и рекомбинирует с образованием перекиси водорода, которая способна подвергаться фотохимическому разложению с формированием активных окислителей - гидроксильных радикалов. Сумма этих явлений описывается предположительно схемой:

$$
\begin{gathered}
\mathrm{ABC} \stackrel{h v}{\longrightarrow}[\mathrm{ABC}]^{*} \longrightarrow\left[\mathrm{ABC}^{\circ}+\mathrm{e}^{-} a q\right. \\
\mathrm{O}_{2}+\overline{\mathrm{e}} a q \longrightarrow \mathrm{O}_{2}^{\circ} \\
\mathrm{O}_{2}^{\circ}+\mathrm{H}^{+} \longrightarrow \mathrm{HO}_{2}^{\circ} ; 2 \mathrm{HO}_{2}^{\circ} \longrightarrow \mathrm{H}_{2} \mathrm{O}_{2}+\mathrm{O}_{2} \\
\mathrm{H}_{2} \mathrm{O}_{2} \stackrel{h v}{\longrightarrow}(2) \mathrm{OH}^{\circ}
\end{gathered}
$$

Таким образом, есть основание полагать, что основой фотоинициированного окисления АБС являются взаимодействие его молекулы со свободными гидроксильными радикалами и протекание реакции ее гидроксилирования. Экспериментальным подтверждением этому предположению является замедление превращения АБС при соокислении с $n$-нитрозодиметиланилином (n-НДMА) - специфичным акцептором $\mathrm{OH}^{\circ}$-радикалов [3] (см. рис. 2). Другим свидетельством участия гидроксильных радикалов в изучаемых реакциях АБС является эксперимент по их фотоокислению в среде этанола - также известного акцептора этих активных окислителей. Из данных, представленных на рис. 3, следует, что скорость фотоокисления АБС в этаноле значительно ниже, чем в водной среде, и она линейно снижается по мере увеличения доли этанола в его смеси с водой. 


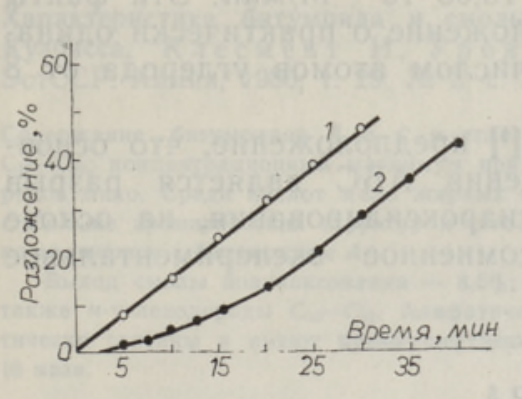

Рис. 1. Кинетика фотодеградации $n$-нонилбензолсульфоната при исходной концентрации $6,54 \cdot 10^{-5} \mathrm{M}$. 1 - без аскорбиновой кислоты, 2 - в присутствии эквимолярного количества аскорбиновой кислоты.

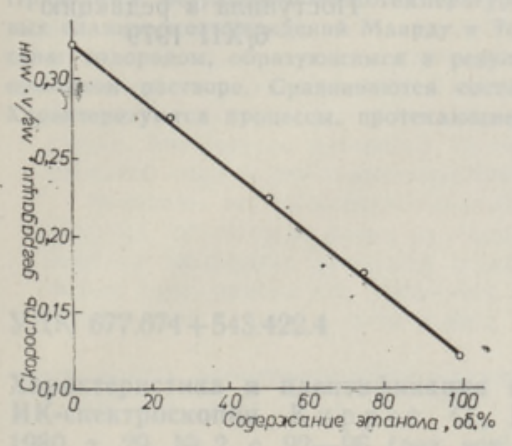

Рис. 3. Зависимость скорости фотоокисления $n$-нонилбензолсульфоната от содержания этанола в смеси с водой.

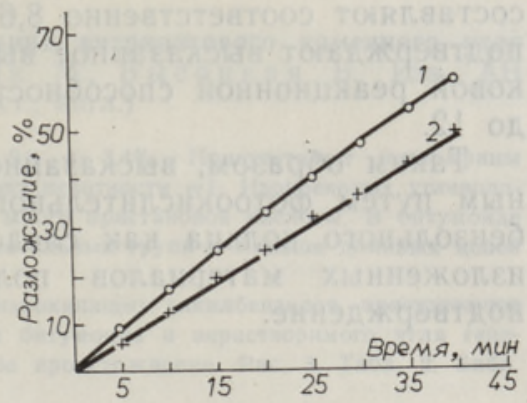

Рис. 2. Кинетика фотоокисления $n$-нонилбензолсульфоната в воде при исходной концентрации $6,54 \cdot 10^{-5} \mathrm{M}$. 1 - без добавки $n$-НДМА, 2 - в присутствии эквимолярного количества $n$-НДМА.

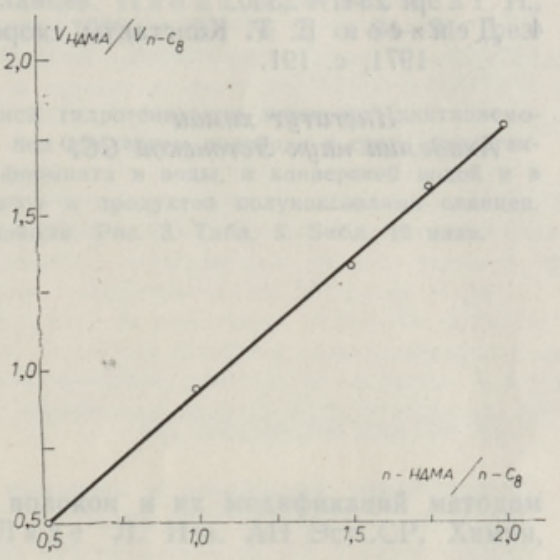

Рис. 4. Зависимость соотношения скоростей фотодеградации $n$-НДМА и n-октилбензолсульфоната от соотношения их концентраций при соокислении в $\mathrm{H}_{2} \mathrm{O}_{2}$.

В последующей серии экспериментов оценена количественно высокая реакционная способность АБС во взаимодействии со свободными гидроксильными радикалами. Основой ее явилось изучение соокисления АБС и $n$-НДМА в облучаемом $0,2 \mathrm{M}$ водном растворе $\mathrm{H}_{2} \mathrm{O}_{2}$ $\left(\mathrm{H}_{2} \mathrm{O}_{2} \stackrel{h v}{\longrightarrow} 2 \mathrm{OH}^{\circ}\right)$. Тангенс угла наклона прямой на рис. 4 представляет собой соотношение констант скорости взаимодействия генерируемых гидроксильных радикалов с $n$-НДМА и АБС и равен 0,875 . Соответственно, константа скорости взаимодействия n-октилбензолсульфоната с радикалами $\mathrm{OH}^{\circ}$ равна $8,57 \cdot 10^{9} \mathrm{M}^{-1} \cdot \mathrm{c}^{-1}$, поскольку аналогичная константа для $n$-НДМА, как известно из [ $\left.{ }^{4}\right]$, составляет $7,5 \cdot 10^{9} M^{-1} \cdot c^{-1}$.

Индукционное влияние алкильного заместителя на реакционную способность АБС в изученном взаимодействии с гидроксильными радикалами, судя по данным дополнительного эксперимента, невелико и затухает по мере удлинения парафиновой цепи. Так, скорости фотоинициируемого окисления $n$-толуол-, кумол- и октилбензолсульфонатов 
составляют соответственно 8,$67 ; 10,00$ и $10,05 \cdot 10^{-7} \mathrm{M} / \mathrm{MLH}$. Эти факты подтверждают высказанное выше предположение о практически одинаковой реакционной способности АБС с числом атомов углерода от 8 до 12.

Таким образом, высказанное нами в ['] предположение, что основным путем фотоокислительного превращения АБС является разрыв бензольного кольца как следствие его гидроксилирования, на основе изложенных материалов получило несомненное экспериментальное подтверждение.

\section{Л ИТ Е РА Т У А}

1. Чекул а в В. Фотоинициированное окисление линейных алкилбензолсульфонатов в водной среде. - Изв. АН ЭССР. Хим., 1979, т. 28, № 3, с. 217-219.

2. Аф ан асьев И. Б. Анион-радикал кислорода О $\frac{\circ}{2}$ в химических и биологических процессах. - Успехи химии, 1979, т. XVIII, вып. 6, с. 976-1014.

3. Kraljić, I., Trumbore, C. N. p-Nitrosodimethylaniline as an $\mathrm{OH}^{\circ}$ radical scavenger in radiation chemistry. - J. Amer. Chem. Soc., 1965, June 20, p. $2547-2550$.

4. Ден и сов Е. Т. Константы скорости гомолитических жидкофазных реакций. М., 1971 , c. 191.

Ннститут химии

Академии наук Эстонской ССР
Поступила в редакцию 6/XII 1979 